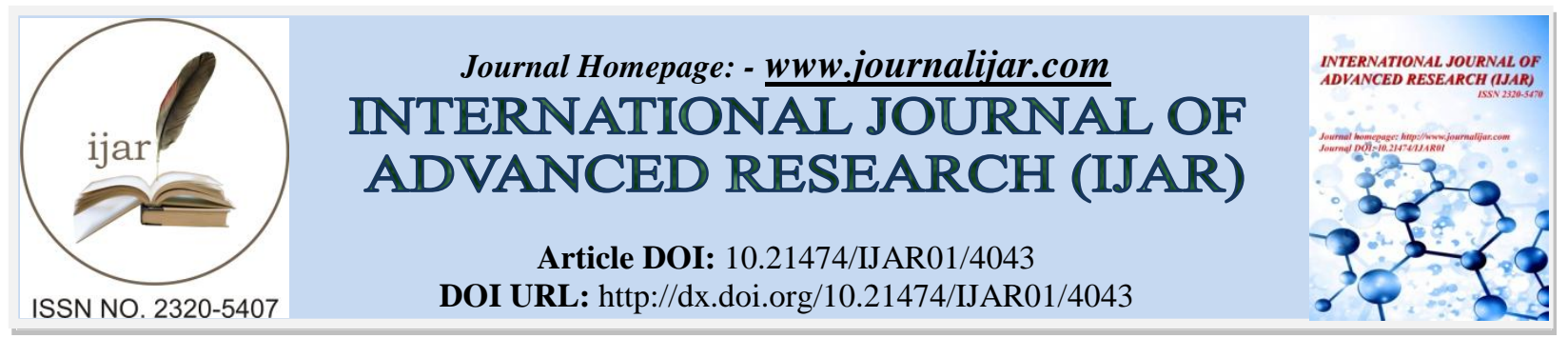

RESEARCH ARTICLE

\title{
EVALUATION OF DENTINAL MICRO CRACK FORMATION BY NEW SELF ADJUSTING FILE SYSTEM VERSUS CONVENTIONAL NITI ROTARY INSTRUMENTS: AN IN VITRO STUDY.
}

\author{
Dr. Pratishtha Tanwar and Dr Ekta Choudhary. \\ Dept. Of Conservative Dentistry And Endodontics.
}

\section{Manuscript Info}

Manuscript History

Received: 16 February 2017

Final Accepted: 21 March 2017

Published: April 2017

Key words:-

Rotary NiTi instruments, dentinal microcracks, stereomicroscope, SAF system.

\begin{abstract}
The aim of this study was to evaluate and compare the dentinal microcrack formation in root dentine by new SAF system and other rotary instruments. This study was performed on 40 single-canal extracted mandibular premolars.

Materials And Methods:- Teeth were divided into 4 groups $(n=10)$, according to their preparation criteria:

Group 1- Control group in which teeth were only prepared with \#20 K file.

Group 2- Teeth were prepared by K3XF (SYBRONENDO) file after glide path preparation with \#20 K file

Group 3- Teeth were prepared by Twisted file system (SYBRONENDO) after glide path preparation with \#20 K file

Group 4- Teeth were prepared by Self Adjusting File system after glide path preparation with \#20 K file.

Results:- In the present study the maximum defects were found in group 3 (twisted file), followed by group 2 (K3XF) and minimum cracks in group 4 i.e SAF system. No defects were observed in group 1 (control). Groups were significantly different from each other $(\mathrm{P}=$ $0.01)$.

Conclusion:-Maximum defects were found in group 3 (twisted file), followed by group $2(\mathrm{~K} 3 \mathrm{XF})$ and minimum cracks in group 4 i.e $\mathrm{SAF}$ system. No defects were observed in group 1(control). The $\mathrm{p}$ value less than $0.05(\mathrm{p}<0.05)$ was considered statistically significant.
\end{abstract}

Copy Right, IJAR, 2017,. All rights reserved.

\section{Introduction:-}

Biomechanical tooth preparation is one of the most important factors for a successful root canal treatment. For a successful root canal therapy proper diagnosis, thorough biomechanical preparation and three dimensional obturation with proper apical sealing is required ${ }^{1}$. One of the important steps in root canal therapy is biomechanical preparation, for which different kind of endodontic instruments or file systems are available in market.It is believed that the biomechanical preparation can leads to dentinal damage which further leads to a vertical root fracture. Dentinal damage can be caused by different factors like dehydration of dentine, by using finger spreader during obturation, preparation technique of root canal, due to endodontic instruments and its design ${ }^{2-3}$. Previously only hand instruments were used which are made up of stainless steel to clean the canal but due to the hardness and stiffness of the metal used for hand instruments, it create canal aberrations, zipping formation, elbow formation, uneven smoothening of walls etc ${ }^{4}$. 
Therefore, to overcome these problems new rotary NiTi instruments have been introduced, which create smoother, more flexible, with less incidence of perforation and transportation of canal walls as compared to hand stainless steel instruments. The specific designs and flexibility of different rotary systems allow maintaining the natural curvature of root throughout the cleaning procedure which prevents the straightening of canal curvature ${ }^{5}$.

Nowadays, NiTi rotary systems are frequently used by the practitioners. The cutting efficacy with good flexibility of rotary files and shortened working time of rotary files provide many advantages over the hand files. But, due to the cutting blade design and configurations, different tapers and tip design of rotary file systems it is believed that the rotary files create more tension, stress and frictional forces against the canal walls, which may cause microcrack formation into the dentine and further these microcracks in dentine which weakens the root dentine and become the most obvious reason for vertical root fracture in future ${ }^{6}$.

In comparison to stainless steel instruments, NiTi files offer increased flexibility, rapid and cantered canal preparation, safer preparation of curved canals, improved cutting efficiency, superior torsional resistance. A main limitation in the use of NiTi instruments is the risk of their fracture, the fracture of rotary NiTi instrument in root canal especially in curved canal can lead to failure of treatment ${ }^{7}$. A new NiTi file system K3 (SybronEndo, Orange, CA) demonstrates a unique cross-sectional design; a slightly positive rake angle for greater cutting efficiency, wide radial lands, and a peripheral blade relief for reduced friction. several new thermo mechanically processed endodontic NiTi files have been introduced to the endodontic market, including K3XF (SybronEndo, Orange, CA), and Twisted Files (TFs; SybronEndo) According to the manufacturer, Twisted File instruments were developed by transforming a raw NiTi wire in the austenite phase into the R-phase through a thermal process ,this file system manufactured in $2008^{8}$. The new system, K3XF, has been available since 2011. K3 and K3XF instruments are identical in shape and differ only in production, where K3XF instruments undergo post-machining heat treatment. The main advantage gained by this specific heat treatment is not only does it improve the flexibility and strength of the file, but also it modifies the crystalline structure of the alloy. This structural modification enables the file to accommodate some of the internal stress caused by the grinding process. Therefore, this new development may eliminate many of the drawbacks experienced by older generation files during the grinding process, and produce an instrument with superior mechanical properties ${ }^{9}$. But all these new rotary file systems consist of a solid central metal shaft with a rotating blade flutes which mainly concentrating on the vigorously shaping of canal by cutting the dentine according to the shape of that rotary file ${ }^{10}$.

In other hand, a new file system known as self adjusting file system was introduced which is completely different from the previous systems. It is a file system designed as a hollow file, which is made up of nickel titanium lattice having abrasive or rough outer surface. It is extremely flexible and compressible; it has a diameter of $1.5 \mathrm{~mm}$ which gets compressed into the canal and takes shape of the canal. Before insertion of SAF, canal should be prepared by a \#20 K file for glide path. Because of the structure of this file which is a hollow lattice meshwork, it adapt itself to the cross sectional shape of the canal. Hence, it is named as "'self adjusting file'". SAF system cannot rotate into the canal as it has a in-and-out vibration created by the RDT handpiece-head. It create very less compressive forces to the dentinal walls and also remove very less dentine as compared to other rotary file system as they have cutting blades $^{11}$.So, the aim of this study is to evaluate and compare the dentinal microcrack formation in root dentine by new SAF system and other rotary instruments.

\section{Materials And Methods:-}

Freshly extracted 40 mandibular, single rooted premolar teeth were used in this study. These teeth were extracted due to the orthodontic reason and stored in purified water. All teeth were decoronated using a diamond disk, with sufficient water cooling to standardize the root length upto $13 \mathrm{~mm}$. After decoronation of all teeth, were examined under stereomicroscope under the magnification of $4 \mathrm{x}$, to check for microcrack or fracture lines, and also preoperative radiograph were taken to confirm single canal in each tooth sample. Working length of all tooth samples were determined by \#10K file (Dentsply Maillefer Ballaigues,Switzerland), and prepared a glide path upto the apical file size of \#20k file at the working length.

Teeth were divided into 4 groups $(n=10)$, according to their preparation criteria:-

Group 1- Control group in which teeth were only prepared with \#20 K file.

Group 2- Teeth were prepared by K3XF (SYBRONENDO) file after glide path preparation with \#20 K file

Group 3- Teeth were prepared by Twisted file system (SYBRONENDO) after glide path preparation with \#20 K file Group 4- Teeth were prepared by Self Adjusting File system after glide path preparation with \#20 K file 
All canals of each group were irrigated with $4 \mathrm{ml}$ of $3 \%$ sodium hypochlorite in between each instrument used during biomechanical preparation and then final rinse was done with $10 \mathrm{ml}$ of purified water for all groups of canals. All roots were kept in moist cotton throughout the experiment.

\section{Examination Of Roots:-}

All teeth were sectioned horizontally at 3,6 and $9 \mathrm{~mm}$ from the root apex (apical third, middle third and coronal third) by diamond disk with straight hand piece, with continuous water cooling, and kept in moist cotton till the microscopic examination.All sections were analysed for dentinal microcracks under stereomicroscope at $12 \mathrm{x}$ magnifications. Dentinal microcracks present in root sections were devided into 3 categories:

1. No Defect- When there is no dentinal microcrack observed.

2. Complete Fracture- When there is a complete fracture line extended from root canal space or lumen, to the outer surface.

3. Partial Fracture- When there is fracture line travels from the lumen but did not reach upto the outer surface.

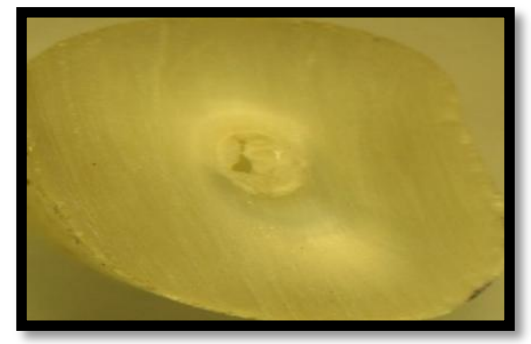

(a) No defect

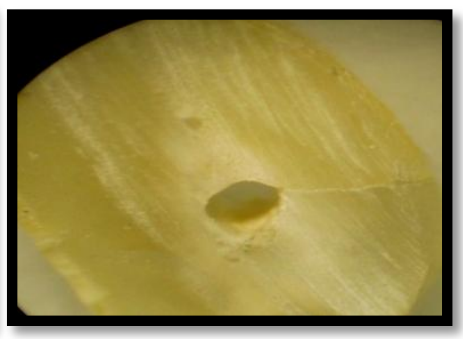

(b) Complete fracture

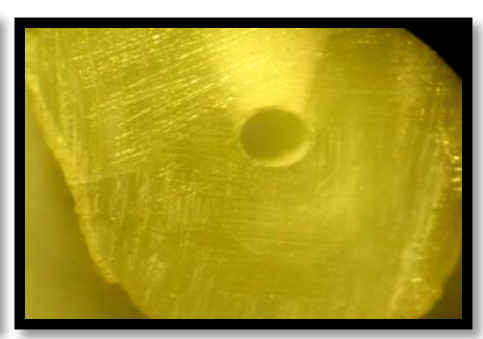

(c) Partial fracture

Figure 1:- Classification of defects (a) No defect (b) Complete fracture (c) Partial fracture

\section{Statistical Analysis:-}

Data was analyzed using SPSS software 17.0 program (SPSS Inc., Chicago). Chi -Square test was performed to determine the significant difference in between the experimental groups and to determine the defects at different horizontal sections in each group. The level of significance was set at $\mathrm{p}<0.05$.

\section{Results:-}

In the present study the maximum defects were found in group 3 (twisted file) may be due to the triangular crosssection of file which improves the cutting efficiency of file, followed by group 2 (K3XF) and minimum cracks in group 4 i.e SAF system. Least defect seen in group 4 may be due to the non cutting feature of the file system as we already discussed that it has a abrasive action on dentinal wall rather than the cutting action. No defects were observed in group 1(control). Groups were significantly different from each other $(\mathrm{P}=0.01)$.

\section{Discussion:-}

As we know dentinal microcrack can be caused by many means like during biomechanical preparation, physical properties of teeth ${ }^{3}$, design of various endodntic instruments and by finger spreader inducing lateral forces during obturaion etc. any of them can lead to dentinal damage that may further induce a vertical root fracture ${ }^{2}$.

Sectioning method used in this study is done by diamond disc, which may be considered as one of the reason for microcrack formation in samples, but we justify this by proving that the control group did not show any microcrack during the stereomicroscopic evaluation so we may conclude that defects seen in other groups are not due to the sectioning method used in this study.

In this study three file systems were used regarding the incidence of dentinal microcrack formation.Twisted file shows maximum defect formation. This could be due the triangular cross section of this file which causes aggressive cutting of the dentinal surface ${ }^{12}$. In comparison the defects were fewer with K3XF possibly due to the presence of radial lands in the file cross section which reduce dentinal friction, facilitating its smoother operation and hence less stress on root dentine ${ }^{13}$. Greater taper, rotational motion are other factors of the rotary files that result in more dentin removal and stress generation which explains the greater number defects seen with rotary instruments ${ }^{14}$. Whereas, SAF shows least dentinal microcracks. SAF is designed as a thin NiTi lattice which gets compressed when inserted into the canal and then attempts to regain its original dimensions and thus applies a constant delicate 
pressure on canal walls which allows uniform removal of dentine along the whole perimeter of root canal cross section $^{15}$. It might be the reason why SAF created least dentinal defect among all the groups.

Table 1:- Comparison of number and percentage of teeth showing defects.

\begin{tabular}{|c|c|c|c|c|}
\hline DEFECT & CONTROL \% & TWISTED FILE\% & K3 FILE \% & SAF \% \\
\hline PRESENT & $0(0 / 30)$ & $30(9 / 30)$ & $16.67(5 / 30)$ & $6.67(2 / 30)$ \\
\hline ABSENT & 100 & 70 & 83.33 & 93.33 \\
\hline TOTAL & 100 & 100 & 100 & 100 \\
\hline
\end{tabular}

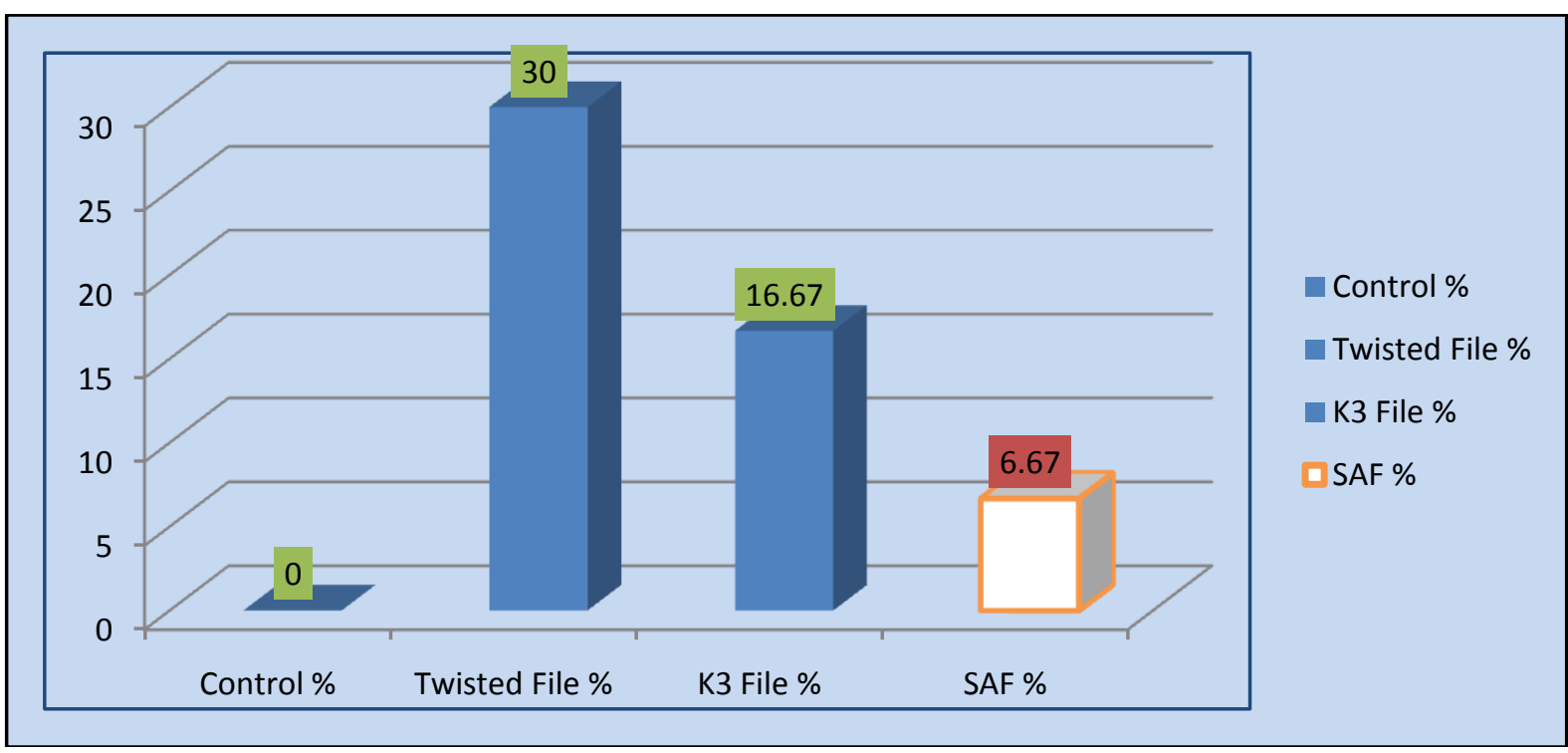

Graph 1:- comparison of defects in percentage $(\mathrm{p}=0.01)$

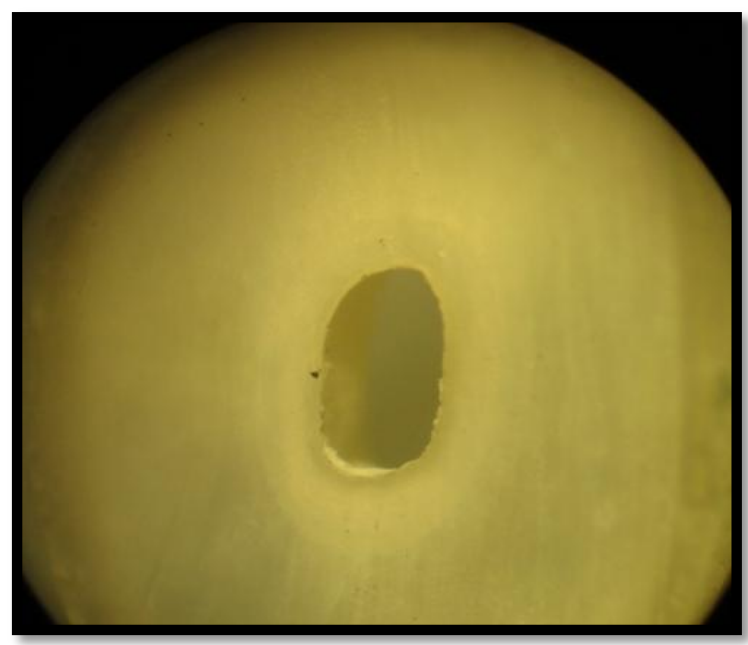

Group 1:-

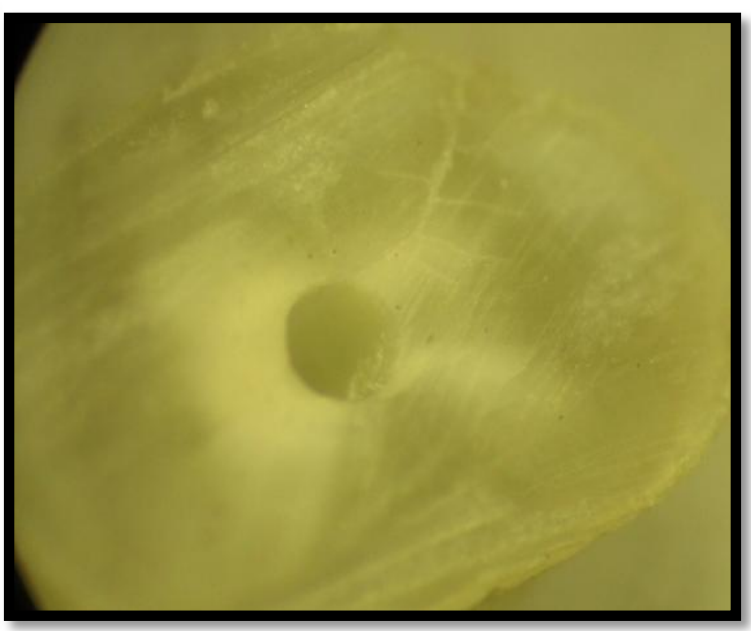

Group 2:- 


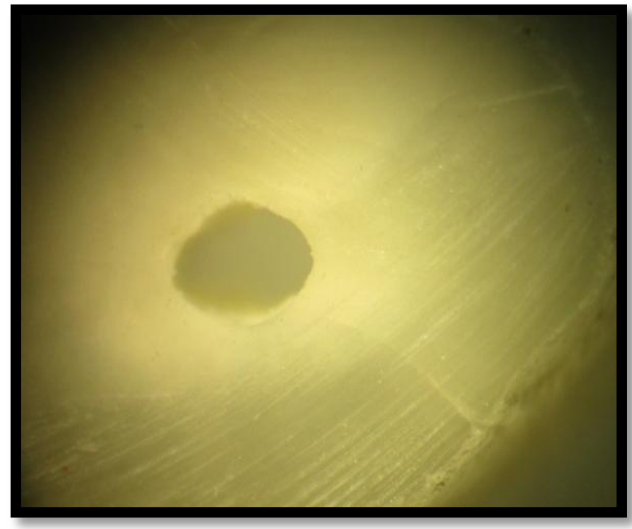

Group 3:-

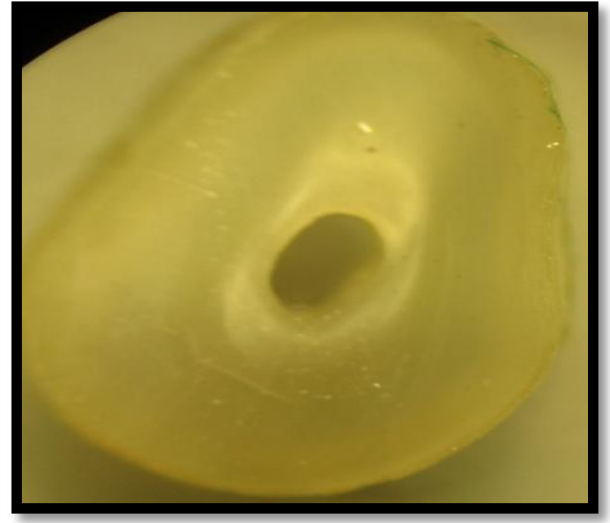

Group 4:-

Figure 2:- Defects seen in different groups.

According to some research $\mathrm{NaOCl}$ can change the mechanical properties of dentine and also affect elastic modulus and flexure strength of dentine which may affect the dentinal microcrack propogation ${ }^{16}$. In this study $3 \%$ sodium hypochlorite was used for irrigation of all group samples. Concentration and amount of sodium hypochlorite were same for all groups, but the control group did not show any dentinal defect, which may consider that the sodium hypochlorite did not contributed in any kind of dentinal defects in this study.

In this study, group 3 in which samples were prepared by self adjusting file showed better result than other rotary file groups. Self adjusting file is hollow and compressible, thin walled mashwork NiTi lattice file. SAF has a in-andout vibrating motion with its handpiece which allow 300-500 vibrations per minute. It has been reported that SAF file can clean ovoid canals much better than any other rotary file because of its compressive nature to adapt itself according to the shape of ovoid canal. Root dentine can be easily preserved by using SAF as it has a scrubbing action and do not cause cutting of dentine. Hence, SAF cause minimal stress on dentinal wall and least dentinal damage ${ }^{17}$.

One of the drawbacks of other NiTi endodontic instruments is that as the size of the file increases in the sequence of enlarging the root canal during instrumentation, the stiffness of the file also increases. This is particularly problematic in curved canals because as the file navigates around the curvature, restoring forces attempt to return the instrument back to its original, straight shape when it is used in a filing motion. This has been shown to lead to procedural errors such as canal transportation, apical zipping, canal ledges, and strip perforations ${ }^{18}$.

In addition, it also causes a thinning of the canal wall on the side of the tooth that the canal transportation occurs, particularly in molar teeth, where anatomical studies have shown that the thickness of root dentin in furcation areas of mandibular molars can be as thin as $1.2 \mathrm{~mm}$. If the transportation of the canal moves towards the furcation, it may result in a perforation of the lateral aspect of the root (strip perforation), which may compromise the prognosis of the tooth $^{19}$. To avoid these dentinal damage some new NiTi files like twisted file were introduced which is flexible but not as much as SAF but still it cause more dentinal damage then SAF and K3XF due to its flutes design, triangular crosssection,taper etc $^{20}$.

\section{Conclusion:-}

This study concluded that the NiTi instruments tend to induce various dentinal defects; on the other hand SAF shows satisfactory results with minimal crack formation. SAF proved as a better system then rotary files as it cause less dentinal defects which decreases the susceptibility of vertical root fracture. 


\section{References:-}

1. Peters OA. Current challenges and concepts in the preparation of root canal systems: a review. Journal of endodontics. 2004;30(8):559-67.

2. Wilcox LR, Roskelley C, Sutton T. The relationship of root canal enlargement to finger-spreader induced vertical root fracture. Journal of Endodontics. 1997;23(8):533-4.

3. Ertas H, Sagsen B, Arslan H, Er O, Ertas ET. Effects of physical and morphological properties of roots on fracture resistance. European journal of dentistry. 2014;18(2):261.

4. Singh S, Nigam N. Comparative evaluation of surface characteristics of dentinal walls with and without using plastic finishing file. Journal of Conservative Dentistry. 2010;113(2):89.

5. Kim HC, Lee MH, Yum J, Versluis A, Lee CJ, Kim BM. Potential relationship between design of nickeltitanium rotary instruments and vertical root fracture. Journal of endodontics. 2010;36(7):1195-9.

6. Kim HC, Lee MH, Yum J, Versluis A, Lee CJ, Kim BM. Potential relationship between design of nickeltitanium rotary instruments and vertical root fracture. Journal of endodontics. 2010;36(7):1195-9

7. Bergmans L, Van Cleynenbreugel J, Beullens M, Wevers M, Van Meerbeek B, Lambrechts P. Smooth flexible versus active tapered shaft design using NiTi rotary instruments. International Endodontic Journal. 2002;35(10):820-8.

8. Bahia MG, Melo MC, Buono VT. Influence of cyclic torsional loading on the fatigue resistance of K3 instruments. International endodontic journal. 2008;41(10):883-91.

9. Bhagabati N, Yadav S, Talwar S. An in vitro cyclic fatigue analysis of different endodontic nickel-titanium rotary instruments. Journal of endodontics. 2012;38(4):515-8.

10. Yoldas O, Yilmaz S, Atakan G, Kuden C, Kasan Z. Dentinal microcrack formation during root canal preparations by different NiTi rotary instruments and the self-adjusting file. Journal of endodontics. 2012;38(2):232-5.

11. Metzger Z. The self-adjusting file (SAF) system: An evidence based update. Journal of Conservative Dentistry. 2014;17(5):401.

12. Karataş E, Gündüz HA, Kırıcı DÖ, Arslan H, Topçu MÇ, Yeter KY. Dentinal crack formation during root canal preparations by the twisted file adaptive, ProTaper Next, ProTaper Universal, and WaveOne instruments. Journal of endodontics. 2015;41(2):261-4.

13. Monga P, Bajaj N, Mahajan P, Garg S. Comparison of incidence of dentinal defects after root canal preparation with continuous rotation and reciprocating instrumentation. Singapore dental journal. 2015;31(36):29-33.

14. Liu R, Hou BX, Wesselink PR, Wu MK, Shemesh H. The incidence of root microcracks caused by 3 different single-file systems versus the ProTaper system. Journal of endodontics. 2013;39(8):1054-6.

15. Solomonov M. Eight months of clinical experience with the Self-Adjusting File system. Journal of endodontics. 2011;37(6):881-7.

16. Sim TP, Knowles JC, Ng YL, Shelton J, Gulabivala K. Effect of sodium hypochlorite on mechanical properties of dentine and tooth surface strain. International Endodontic Journal. 2001;34(2):120-32.

17. Kim HC, Sung SY, Ha JH, Solomonov M, Lee JM, Lee CJ, Kim BM. Stress generation during self-adjusting file movement: minimally invasive instrumentation. Journal of endodontics. 2013;39(12):1572-5.

18. Haapasalo M, Shen Y. Evolution of nickel-titanium instruments: from past to future. Endodontic topics. 2013;29(1):3-17.

19. Berutti E, Fedon G. Thickness of cementum/dentin in mesial roots of mandibular first molars. J Endod. 1992;18(11):545-8.

20. Aydin C, Inan U, Gultekin M. Comparison of the shaping ability of Twisted Files with ProTaper and RevoS nickel-titanium instruments in simulated canals. Journal of Dental Sciences. 2012;7(3):283-8. 